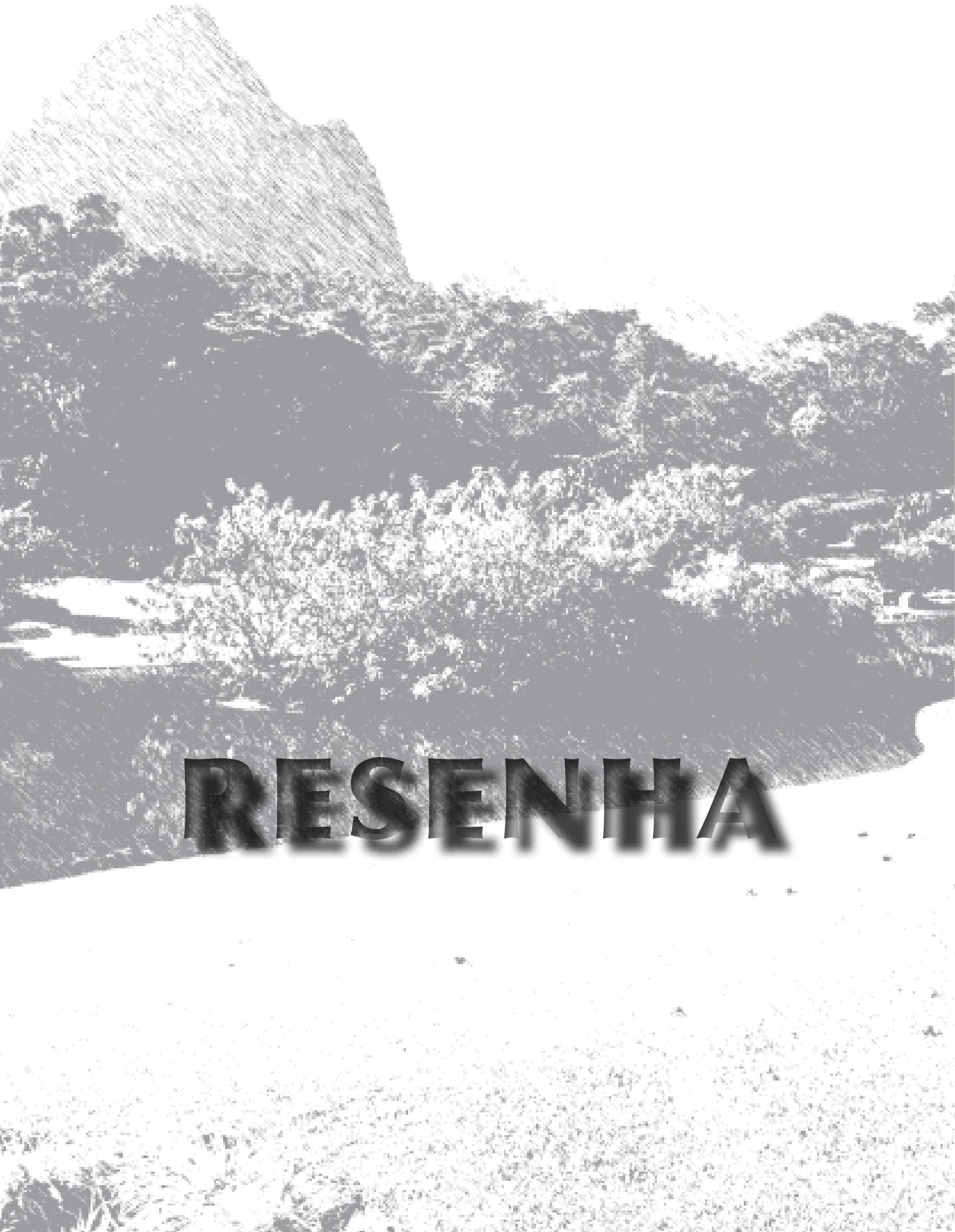




\section{A HERANÇA DE UMA MODERNIDADE}

\section{Vladimir Bartalini}

Arquiteto e professor da Faculdade de Arquitetura e Urbanismo da Universidade de São Paulo

Passados 15 anos da morte de Roberto Burle Marx e 100 anos de seu nascimento, entre as homenagens que a data propicia, vem a público Modernidade verde: Jardins de Burle Marx, de Guilherme Mazza Dourado. Não que a feitura do livro tivesse esse objetivo, mas seu lançamento, neste momento, é muito oportuno. Na verdade, ele provém da dissertação de mestrado, apresentada pelo autor em 2000, com tratamento tão cuidado de texto e de imagens que já fazia supor o futuro livro. De fato, logo em seguida começaram os trâmites para a publicação. Os nove anos transcorridos dão a medida dos entraves do meio editorial no Brasil, mesmo quando se lida com um assunto e com a obra de um paisagista cujo interesse está longe de ser esgotado, e ainda que se alegue a imensa desproporção entre as publicações sobre Burle Marx e aquelas dedicadas a outros paisagistas brasileiros.

Vale lembrar que durante muito tempo, mais precisamente por 20 anos, The tropical gardens of Burle Marx, de Pietro Maria Bardi, com excelentes fotografias de Marcel Gautherot (Colibris Editora Ltda., Amsterdã - Rio de Janeiro, 1964), era tudo com que as bibliotecas especializadas no Brasil podiam contar sobre o conjunto da

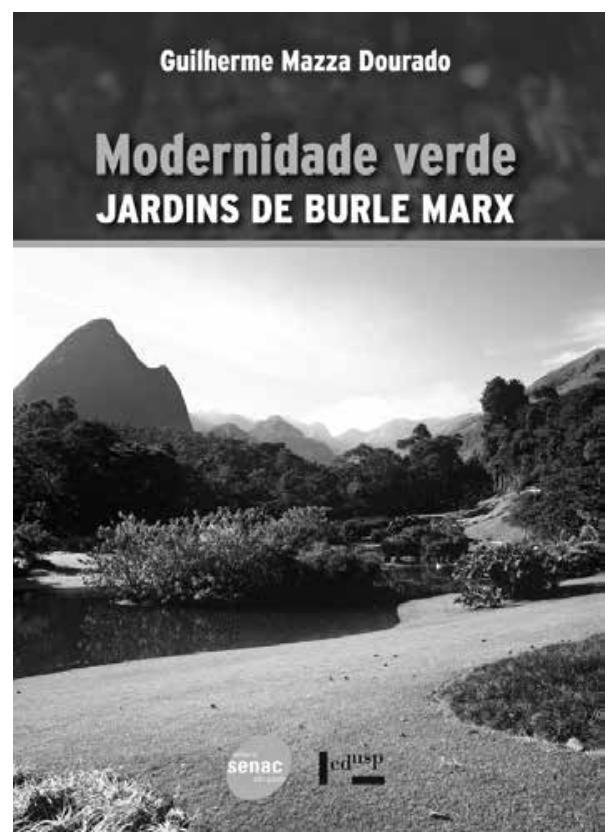

Capa do livro: Modernidade verde: Jardins de Burle Marx

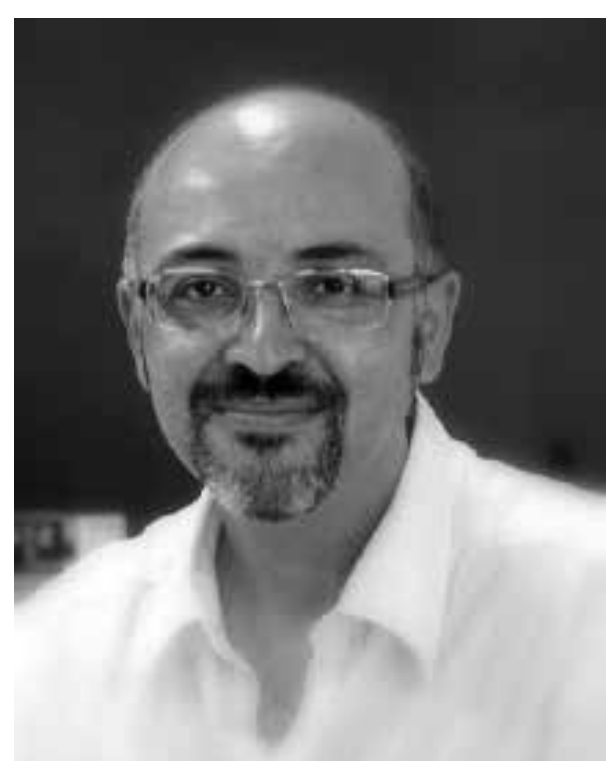

Guilherme Mazza Dourado 
obra do artista, além do texto escrito em inglês, alemão e italiano, sem uma única linha em português (diante disso, ressalta o mérito da Publicação n. 1 do Museu da Faculdade de Arquitetura e Urbanismo da Universidade de São Paulo, de 1971, uma brochura dedicada a Burle Marx, com dois textos de sua autoria e uma bibliografia dominada por artigos em revistas de arquitetura e em jornais). Só em 1984 a Nobel lançou o estudo de Flávio Motta (com fotografias do mesmo Gautherot) intitulado Roberto Burle Marx e a nova visão da paisagem, ensaio que apontava para as possibilidades de emancipação da natureza explorada da ex-colônia tropical, em direção a uma paisagem urbana humanizada, presentes na obra do paisagista. A partir de então, a intervalos bem menores, outras publicações em português se sucederam, seja na forma de compilação de textos seus (Roberto Burle Marx. Arte e paisagem, Nobel, 1987, com segunda edição pela Studio Nobel, em 2004), biografia ilustrada (Roberto Burle Marx, um retrato, por Laurence Fleming, editora Índex, 1996), seja em organização de textos sobre Burle Marx (Nos jardins de Burle Marx, por Jacques Leenhardt, tradução de Pérola de Carvalho, Perspectiva, 1996). Além dessas, já se pode contar, hoje, com várias publicações integralmente dedicadas a Burle Marx, ou que lhe reservam um capítulo especial, editadas no exterior.

Todas fazem referência, com acentos variados, aos múltiplos dons e interesses de Burle Marx: paisagismo, pintura, tapeçaria, joalheria, música, botânica, culinária. Difícil mesmo não relacioná-los; os procedimentos analíticos, geralmente, não dão conta do fazer artístico, menos ainda no caso de um artista que se manifestava (e com que propriedade!) mediante recursos tão diversos.

Guilherme Mazza Dourado, em Modernidade verde, não deixa de referir-se às viagens botânicas empreendidas por Burle Marx (com a transcrição de excertos de suas observações, na qual se fundem curiosidade científica e fruição estética), nem aos seus desenhos e pinturas, mas não cede à facilidade das transposições imediatas. Se as formações naturais impressionaram fortemente o excursionista, ele as artializava (para usar a palavra que Alain Roger toma emprestado de Charles Lalo o qual, por sua vez, encontrou-a em Montaigne) em seus jardins de modo a não diluí-los na natureza. Do mesmo modo, as cores e as formas que povoam suas pinturas e jardins e certas técnicas e estratégias comuns de sua utilização não autorizam inferir uma comunicação direta entre os dois meios de expressão. De fato, entre os anos 1930 e 1950, informa o autor: "(...) quando Burle Marx passava a selecionar um repertório vegetal de cores intensas e briIhantes, experimentando harmonias cada vez mais contrastantes no paisagismo, sua pintura transitava nas cores e matizes rebaixados, no jogo sutil de associações cromáticas que se libertava paulatinamente da representação realista."

Arquiteto de formação, o autor, diante dos múltiplos interesses e da vasta produção de Burle Marx, concentra-se no paisagismo in situ, nos jardins realizados no Brasil, dos anos 30 aos meados da década de 1960, espaço e tempo em que sua linguagem se desenvolveu e ganhou expressão máxima, tecendo 
a flora e a luz tropicais, as formas e as cores em diálogo com os movimentos estéticos que lhe eram contemporâneos. Sua obra paisagística, caracteristicamente brasileira e, ao mesmo tempo, universal, alcançou, então, reconhecimento amplo, dentro e fora do país.

É comum tratar personagens da estatura de Burle Marx como gênios auto-engendrados, nascidos do nada. Não é esse o caso de Modernidade verde. Mazza Dourado situa Burle Marx em seu tempo, imerso em uma "brasilidade" em gestação, tanto nas artes plásticas, na arquitetura, na música, na literatura e na poesia quanto também no paisagismo, pelas experiências de Flávio de Carvalho e Mina Klabin Warchavchik.

Na primeira parte do livro, intitulada "Descoberta da natureza", o autor recua mesmo ao século 19 para dar os créditos ao naturalista alemão Ludwig Riedel pela divulgação de plantas ornamentais nativas e sua utilização em espaços públicos no Rio de Janeiro, e ao botânico e paisagista francês Auguste Glaziou, que também as empregou no período em que foi responsável pelos espaços ajardinados da capital do império e, depois, da república. Ambos permaneceram no Brasil em torno de quatro décadas transcorridas sucessivamente - o primeiro, de 1820 a 1861, o segundo de 1858 a 1897 - , tempo suficiente para semear e cultivar idéias que, se não chegaram a ser, então, hegemônicas, nutriram nosso modernismo. Não custa lembrar que, quando Burle Marx nasceu, fazia apenas 12 anos que Glaziou deixara o Brasil. Pode-se dizer que respiraram o mesmo ar.

Na segunda parte, "Estética tropical", são apontadas marcas históricas das sintaxes jardinísticas, cuja contribuição está, em diferentes medidas, presente e reconhecível em Burle Marx: os canteiros clássicos que culminaram nas ricas texturas, desenhos e cores dos parterres franceses do século 17, a absorção das formas da paisagem pelos ingleses no 18, a valorização do informal por William Robinson e o colorismo de Gerturd Jekyll durante a segunda metade do 19 e começo do 20. Ainda que por meio de pinceladas rápidas, essas remissões de Mazza Dourado ajudam a contextualizar, de modo mais abrangente, o fenômeno Burle Marx.

O leitor é assim preparado para apreciar e aproveitar melhor os projetos da fase mineira e os das serras fluminenses que compõem esse capítulo. Trata-se de jardins particulares, residenciais ou não, que se tornaram antológicos pelas relações estabelecidas entre jardim e paisagem, pelos ensaios bem-sucedidos com formas, texturas e cores, pela pesquisa e princípios que embasaram a escolha da vegetação.

A informação não chega apenas pelos registros fotográficos - alguns, emprestados de acervos, são da época da execução dos projetos, outros foram tomados em anos mais recentes -, mas é enriquecida por desenhos técnicos ou de apresentação, com a relação dos vegetais empregados e, sobretudo, pelas descrições de Mazza Dourado. Não é coisa comum. No geral, tudo se resume em capturar o olhar, objetivo facilitado pela própria qualidade dos jardins e 
das fotografias e em apontar as espécies vegetais que ali comparecem, ou a comentários que se aplicam ao conjunto da obra do paisagista. $\bigcirc$ autor, ao contrário, detém-se nos casos, relata as condições que envolveram os projetos e dá sentido à listagem vegetal, ao referir-se ao papel que cada planta ou grupo de plantas desempenha no espaço idealizado por Burle Marx. Essa estratégia de conduzir pela palavra, e não só pela visão, é decisiva no momento de abordar os projetos de paisagismo do Grande Hotel e do Golfe Clube da Pampulha, não-executados. Com base nas informações dos desenhos técnicos do acervo Burle Marx \& Companhia, Mazza Dourado, literalmente, percorre os jardins inexistentes, proporcionando-nos uma experiência singular.

Ainda nessa seção do livro é exposta a polêmica instaurada no meio arquitetônico internacional, nos anos 40 e 50, entre racionalistas e organicistas. A menção só ganhará pleno sentido no capítulo seguinte, "Criando lugares", no concernente aos projetos de espaços públicos de uso comum ou associados a empreendimentos estatais. De um lado, os defensores de uma linguagem universal, asséptica, apoiada na máquina e nas conquistas da técnica; de outro, os que faziam valer os contextos específicos e atentavam para as formas e funcionamento dos organismos.

Sabe-se dos efeitos, benéficos até, desse embate na arquitetura brasileira, mas seu rebatimento no paisagismo é pouco comentado. No entanto, ao discorrerem sobre o tratamento que convinha a um jardim público e a um privado, vários tratadistas do século 18 explicitavam as oposições formais, tidas como necessárias, entre um e outro. Não se pretende, aqui, levar a comparação ao pé da letra, mesmo porque o que alimentava as posições favoráveis à clareza absoluta, ao formalismo, à geometria e à simetria nos jardins públicos, naquela época, não eram propriamente, ou tão-somente, as expectativas de superação do atraso e da ignorância e de conquista da liberdade depositadas no avanço da ciência e das técnicas, mas antes a busca da ordem, mediante o efeito disciplinador da geometria, além dos preconceitos, com doses de paternalismo, no jeito de lidar com o grande público. Desse modo, aos jardins das cidades "convêm a simplicidade e a simetria", dizia Watelet, e mesmo Hirschfeld, que admitia a variedade e a irregularidade em algumas partes dos jardins públicos de uma certa dimensão, considerava que "as custosas obras de arte, as decorações elegantes e as plantas raras que exigem cuidados não convêm a este tipo de jardim", acrescentando que, "todavia, é possível neles dispor obras aptas a produzir impressões úteis sobre a multidão". A diversidade requintada de ambientes, a sutileza, a arte, a poesia, eram reservadas aos proprietários dos grandes jardins privados e aos seus convivas.

A superação dessa dicotomia é o que mais chama a atenção nos projetos de espaços públicos, do Recife ao Rio de Janeiro, compilados na última seção do livro. Neles, independentemente das formas provirem de máquinas ou de organismos, e mais do que a associação magistral entre jardim, arte e arquite- 
tura, desponta o princípio de dedicar ao que é público o mesmo entusiasmo, sensibilidade e refinamento dispensados aos jardins privados, tudo isso em plena vigência das idéias modernistas.

apreço ao espaço público está longe de ser estranho à cidade do modernismo, como não o foi para a cidade tradicional. Disso sobram provas nas declarações, nas Cartas e também nas realizações que muitas cidades, algumas das nossas, inclusive, ostentam. $\bigcirc$ surpreendente é essa atenção voltada aos jardins públicos, que a cidade oitocentista conheceu, mas que o modernismo renegou.

Nisso pode estar uma chave de interpretação do próprio título do livro: Modernidade verde: Jardins de Burle Marx. A modernidade vem ali qualificada; trata-se de uma certa modernidade. Mas o verde ainda não é distintivo suficiente, pois foi cor que não faltou nem no papel, nem, efetivamente, nas proposições e realizações modernas, em todos os lugares. Os jardins, ao contrário, foram banidos. Jean-Pierre Le Dantec aponta algumas das razões: a suposta incompatibilidade entre o mundo industrial, democrático e urbano e a tradição rural e aristocrática à qual a arte dos jardins esteve comumente associada; a estandardização, a internacionalização, a velocidade, enfim, o modo de vida característicos da era industrial versus a singularidade do sítio, a duração do tempo, os cuidados constantes incorporados nos jardins. Além disso, para atender às questões de salubridade e do lazer de massa, tratadas em termos de "necessidades" da sociedade urbano-industrial, as áreas ou espaços verdes, em suma, o verde genérico, era o que bastava.

Os jardins de Burle Marx se inscrevem em outra agenda, criando lugares (e lugares democráticos), não simplesmente áreas verdes. Estudioso e defensor da ecologia das paisagens, militante de políticas abrangentes de preservação de nossos recursos paisagísticos, Burle Marx não descurou da arte e das minúcias que os lugares requerem.

assunto tem relevância atual, o que justifica, afora as homenagens devidas ao centenário do paisagista e as qualidades intrínsecas do livro de Mazza Dourado, mais essa publicação sobre Burle Marx. Quando se faz a crítica à espetaculosidade, ao desperdício, ao supérfluo, é tentador colocar os jardins no mesmo balaio das excentricidades que só consomem recursos materiais e humanos e não dão nada em troca. As consciências mais preocupadas com nosso futuro comum, e não tanto com as chamadas "necessidades do espírito", irão se apegar à causa ambientalista. Outros, que ainda vêem algum sentido no paisagismo, mas não se sentem à vontade para associá-lo à arte, apõe-lhe o epíteto "útil" e medem seu valor pelos serviços prestados, enquanto outros encontram uma saída nas vantagens ao mesmo tempo ecológicas e econômicas do "jardim selvagem" (wild garden), nele presumidos os baixos custos de manutenção. Ocorre que, nas condições de hoje, mesmo o jardim selvagem não dispensa o monitoramento para ser preservado; portanto, também exige 
cuidados. Tampouco seu conceito, originalmente radical, escapa do glamour dos produtos de grife.

Não podemos nos evadir do cuidar, do tratar, do manter. Se a modernidade, e com ela a industrialização, encerrava a promessa de livrar-nos do jugo de lidar com a terra e de substituir, por fim, todo trabalho humano pelo trabalho das máquinas, não nos liberou da necessidade de manter as máquinas. E não saber das máquinas, nem como mantê-las, nem como conservar as coisas que elas produzem, consumindo-as e descartando-as compulsiva e automaticamente, aprofunda o fosso de nossa alienação. Tudo precisa ser cultivado - como se cultivam as amizades, as habilidades, o ócio e até os vícios e os entretenimentos (aliás, entreter é também manter, conservar) - pois a obra humana, deixada ao abandono, retorna à Terra, ao fundo escuro, à noite, no dizer de Dardel, e volta a ser "pedra, madeira e metal".

A herança dos jardins de Burle Marx (e de tudo o que venha a merecer o nome de jardim) não deveria ser vista como um fardo ou um anacronismo. Eles são lugares privilegiados onde estão condensadas as representações de nossa experiência com a Terra, que transformamos em nosso mundo. Faz sentido manter e transmitir essa herança, cultivá-la, se acreditarmos que nem tudo se reduz a produzir tênis mais baratos. 


\section{NORMAS PARA PUBLICAÇÃO- REVISTA PAISAGEM E AMBIENTE: ENSAIOS}

1 Conselho Editorial da revista Paisagem e Ambiente: Ensaios decidirá quais artigos, ensaios, conferências, debates, resenhas, relatos de experiências e notas técnicas terão a possibilidade de publicação, considerando-se para tanto a consistência teórica e a pertinência do tema diante da linha editorial.

2. Apresentação dos trabalhos:

Em mídia eletrônica (CD, DVD), utilizando o processador de texto WORD 6.0 ou superior. Deverá conter entre 21.600 a 43.200 caracteres, incluindo o resumo, o abstract e a introdução. Deverão ser entregues, com o CD/DVD, três cópias impressas do arquivo.

resumo e o abstract não deverão ultrapassar 2.800 caracteres.

3. Os títulos e os subtítulos deverão aparecer em maiúsculas, pois é importante que no original fique clara sua natureza. Também deverão ser concisos e explícitos quanto ao conteúdo tratado. Deverão ser apresentadas, no mínimo, 5 palavras-chave (unitermos).

As contribuições deverão ser acompanhadas da versão em língua inglesa do título, subtítulo, resumo e palavras-chave.

4. Logo após o título, devem constar o nome do autor, sua qualificação, procedência e endereço postal e/ou eletrônico.

5. As notas e referências bibliográficas deverão ser agrupadas no final do texto e devidamente referenciadas, de acordo com as normas NBR 6023 e NBR 10520, da ABNT.

As notas e referências deverão seguir os seguintes padrões:

5.1. Artigos e capítulos de livros

Colocar a referência bibliográfica nesta ordem: autor, título do artigo/ capítulo, nome do autor do livro, título do livro (em itálico), subtítulo (sem itálico), edição, local de publicação (cidade), editora, volume, data de publicação, série ou coleção.

Exemplos

- autor do capítulo e do livro

MACEDO, Silvio Soares. Ecletismo. Quadro do paisagismo no Brasil. São Paulo: Edição do autor, 1999 (Coleção Quapá).

- autor somente do artigo ou capítulo 
MACEDO, Silvio Soares. Robero Burle Marx and the founding of Modern Brazilian Landscape Architecture. In: VACCARINO, R. (E.) Roberto Burle Marx. Landscapes reflected. Nova York: Princenton Architectural Press, 2000.

\subsection{Artigos publicados em periódicos}

Indicar o autor do artigo, título do artigo, subtítulo do artigo, título da revista (em itálico), local de publicação (cidade), título do fascículo, se houver (suplemento ou número especial), volume, número, páginas (inicial e final), mês e ano.

\section{Exemplo}

PELLEGRINO, Paulo Renato Mesquita. Pode-se planejar a paisagem? Paisagem e Ambiente: Ensaios, São Paulo, n. 13, p. 159-179, 2000.

\subsection{Citações no corpo do texto - Referências bibliográficas}

As citações, quando forem literais, devem ser precisas, grafadas em itálico e entre "aspas". No corpo do texto devem constar o sobrenome do autor, data e páginas da publicação. Ex.: (LEITE, 1994, p. 86)

Nas Referências bibliográficas, o sobrenome do autor citado deve ser posto em ordem alfabética (em maiúsculas), prenome, título do livro (em itálico), subtítulo (sem itálico), edição, local de edição (cidade), editora, volume, ano de publicação, série ou coleção (entre parênteses).

\section{Exemplo}

LEITE, Maria Angela Faggin Pereira. Destruição ou desconstrução? Questões da paisagem e tendências de regionalização. São Paulo: Hucitec, 1994.

\subsection{Dissertações e Teses}

As referências de tese de doutorado ou dissertação de mestrado devem conter: nome do autor, título (em itálico), subtítulo (sem itálico), data, número de páginas ou volume, categoria (grau), identificação da instituição, local, data de publicação.

\section{Exemplo}

QUEIROGA, Eugenio Fernandes. A megalópole e a praça: $O$ espaço entre a razão de dominação e a ação comunicativa. 2001. 351 p. Tese (Doutorado) - Faculdade de Arquitetura e Urbanismo, Universidade de São Paulo, São Paulo, 2001.

6. As ilustrações deverão ser entregues em folhas separadas com as devidas indicações de créditos e legendas, devidamente referenciadas no texto.

Os desenhos deverão ser entregues em arte-final, preferencialmente a nanquim sobre papel schoeller. No caso de imagens, deverão ser entregues os originais, para serem escaneados no Laboratório de Programação Gráfica.

Em caso de arquivo eletrônico, a imagem deverá ter 300 d.p.i., no tamanho $12 \times 15$ cm, em RGB. As imagens não serão recebidas por correio eletrônico. 
Será permitida a inclusão de ilustrações que poderão ser impressas em cores, dependendo da disponibilidade de recursos para a impressão. As ilustrações (fotos, desenhos, esquemas e croquis) poderão ocupar um número equivalente de páginas daquelas ocupadas pelo texto.

7. Não serão aceitas reproduções de imagens publicadas em livros, revistas ou periódicos, sem a expressa autorização do(s) autor(es) das mesmas.

8. Após o ato de entrega, as condições dos originais serão analisadas criteriosamente. Os trabalhos que estiverem em desacordo com os padrões aqui descritos serão devolvidos em seguida para que se providencie sua regularização.

9. Os textos assinados serão de inteira responsabilidade dos autores e não haverá alteração de seu conteúdo sem prévia autorização.

10. Os autores receberão gratuitamente três exemplares do fascículo no qual constar publicada sua contribuição. 
